\author{
С. С. Утгоф, В. О. Куневич
}

Белорусский государственный технологический университет

\title{
АНАЛИЗ СОВРЕМЕННЫХ ТЕХНОЛОГИЙ ТЕРМОМЕХАНИЧЕСКОГО МОДИФИЦИРОВАННИЯ ДРЕВЕСИНЫ
}

Мягколиственные породы древесины являются одним из основных ресурсов для деревообрабатывающей промышленности, но низкая прочность и жесткость, небольшой срок службы, невыразительные цвет и текстура ограничивают их применение в качестве облицовочных материалов. Большинство мягколиственных пород отличаются быстрым ростом, следствием чего является высокий процент возобновляемости. В связи с этим проводятся исследования по улучшению эстетических, физических и механических свойств, таких как твердость и прочность древесины, без применения химических составов. В качестве способа улучшения физико-механических свойств древесины широко применяется метод термомеханического модифицирования.

В данной работе обоснована необходимость исследования и развития технологий термомеханической модификации древесины. Рассмотрены уже существующие и применяемые способы модификации. Проведен анализ исследований на тему модифицирования древесины термомеханическим путем, описаны методики и применяемое оборудование. Целью данного анализа является необходимость нахождения оптимальных режимов обработки мягколиственных пород древесины для получения деталей, по физико-механическим свойствам не уступающих аналогичным деталям из твердолиственных пород древесины. Выбор оптимальных режимов может обеспечить применение высокопроизводительного оборудования.

В ходе проведения анализа информации из литературных источников установлены оптимальные диапазоны значений технологических факторов, таких как давление $(P$, МПа), температура $\left(t,{ }^{\circ} \mathrm{C}\right)$ и время $(\tau, \mathrm{c})$, для проведения дальнейших испытаний.

Ключевые слова: прессование древесины, термическая обработка, физико-механические свойства, прочность.

Для цитирования: Утгоф С. С., Куневич В. О. Анализ современных технологий термомеханического модифицированния древесины // Труды БГТУ. Сер. 1, Лесное хоз-во, природопользование и перераб. возобновляемых ресурсов. 2021. № 1 (240). С. 176-181.

\section{S. S. Utgof, V. O. Kunevich \\ Belarusian State Technological University \\ THE ANALYSIS OF MODERN TECHNOLOGIES OF THERMO-MECHANICAL MODIFICATION OF WOOD}

Soft-leaved wood species are one of the main resources for the wood-processing industry, but their low strength and rigidity, short service life, and inexpressive color and texture limit their use as facing materials. Most soft-leaved species are characterized by rapid growth, resulting in a high percentage of renewability. In this regard, research is being conducted to improve the aesthetic, physical and mechanical properties, such as the hardness and strength of wood, without the use of chemical compounds. Thermomechanical modification is widely used as a method for improving the physical and mechanical properties of wood.

This paper substantiates the need for research and development of technologies for thermomechanical modification of wood. Existing and applied modification methods were considered. The analysis of research on the topic of modification of wood by thermomechanical means is carried out, the methods and equipment used are described. The purpose of this analysis is the need to find optimal processing modes for softwood to obtain parts with physical and mechanical properties that are not inferior to those of hardwoods. The choice of optimal modes can provide a choice of highperformance equipment.

During the analysis of information from the literature, optimal ranges of values of technological factors, such as pressure $(P, \mathrm{MPa})$, temperature $\left(t,{ }^{\circ} \mathrm{C}\right)$ and time $(\tau, \mathrm{C})$, were established for further testing.

Key words: wood pressing, heat treatment, physical and mechanical properties, strength.

For citation: Utgof S. S., Kunevich V. O. The analysis of modern technologies of thermo-mechanical modification of wood. Proceedings of BSTU, issue 1, Forestry. Nature Management. Processing of Renewable Resources, 2021, no. 1 (240), pp. 179-181 (In Russian). 
Введение. Древесина используется на протяжении всей истории благодаря своим прочностным характеристикам, стоимости и возобновляемости. В настоящее время наблюдается рост спроса на древесину в связи с демографическим и экономическим ростом в мире. Считается, что в будущем лесное хозяйство не сможет удовлетворить потребности производства по переработке древесины. В связи с этим большое внимание уделяется лесопосадкам и быстрорастущим древесным породам с низкой плотностью. Для улучшения существующих свойств или придания новых используют такие технологические методы модификации, как пропитка, прессование и термообработка. Использование одного из способов или совместная комбинация позволяет повысить прочность, формоизменяемость, антифрикционные свойства и др. Так, в процессе пропитки вещества, проникающие в полость клеточной стенки древесины, увеличивают прочность и стабильность размеров, а проведение процесса прессования способствует повышению плотности. Термическая обработка во всех случаях способствует закреплению приобретенных свойств. Интересным является изучение совместного действия двух или нескольких методов модификации древесины. Актуальным остается вопрос о получении модифицированной древесины, по стоимости дешевле древесины твердых лиственных пород, при этом способной стать полноценным ее заменителем. Помимо данных задач, необходимо реализовывать повышение спроса и более широкое применение древесины быстрорастущих лиственных пород в производстве. Поэтому для каждой исследуемой породы и под каждую поставленную задачу требуется разрабатывать индивидуальные оптимальные режимы обработки.

Основная часть. Целью данной работы является анализ собранных сведений о режимах термомеханической обработки древесины лиственных пород. Для исследования в качестве метода модификации было выбрано термомеханическое модифицирование, так как этот метод экологически чистый и в дальнейшем полученный материал может считаться безопасным.

К настоящему времени известно несколько способов термомеханического модифицирования древесины. К ним относятся: непрерывная усадка под давлением, модификация со ступенчатым прессованием, с предварительным нагревом, с предварительным пропариванием $[1,2]$.

При первом методе древесина нагревается и уплотняется между плитами пресса при давлении 15-35 МПа и температуре $t=140-160^{\circ} \mathrm{C}$. Образцы выдерживают в прессе до 14400 с.
При ступенчатом методе прессования образцы влажностью $W=8 \%$ и температуре $t=(20 \pm 2)^{\circ} \mathrm{C}$ подвергаются ступенчатому прессованию с давлением плит пресса в диапазоне от 1,5 до 5,0 МПа. Затем, с увеличением температуры до $135^{\circ} \mathrm{C}$, образцы выдерживаются под давлением $P=5$ МПа в течение 2400 с. Охлаждение происходит в сжатых плитах пресса до полного остывания. Данный метод позволяет сократить время уплотнения, но количество плит пресса должно соответствовать количеству ступеней прессования.

Для автоматизации данного процесса необходима сложная система передачи образцов от одного объекта к другому.

При методе прессования с предварительным нагревом образцы влажностью $W=8 \%$ помещаются в камеру при температуре $t=$ $=100^{\circ} \mathrm{C}$ и влажности $W=87 \%$ для нагрева в течение 1200 с. После этого уплотняются в прессе при температуре $t=135^{\circ} \mathrm{C}$ и постоянном удельном давлении $P=5$ МПа. Далее, при сохранении давления, температура плит пресса увеличивается до $t=140^{\circ} \mathrm{C}$ и образцы прессуются в течение 1200 с. Охлаждение также происходит в плитах пресса до полного остывания. Предварительное нагревание в сушильных камерах заготовок позволяет значительно сократить время дальнейшего прессования, которое составляет 2700-4200 с, в зависимости от толщины образцов. Это делает возможным применение прессования древесины в производственных масштабах с применением многоэтажных гидравлических прессов [3, 4].

Метод уплотнения древесины с предварительным пропариванием отличается от предыдущего метода тем, что заготовки, высушенные до влажности $W=15 \%$, предварительно пропариваются при температуре водяного пара $t=$ $=100-105^{\circ} \mathrm{C}$ в специальных камерах под давлением до 0,101 МПа в течение 2400-3600 с в зависимости от размера заготовок. Прессование происходит при температуре $t=100-105^{\circ} \mathrm{C}$ и удельном давлении $P=15-29$ МПа. Заготовки после прессования подвергаются сушке в сушильных камерах, а затем охлаждаются. Достоинством этого метода являются меньшие усилия при прессовании, так как пропаренная древесина пластична и требует меньших усилий для упрессовки, соответственно, возможно применение прессов с меньшей мощностью. Однако главный минус данного метода заключается в необходимости большого количества прессформ, что усложняет организацию пространства производства модифицированной древесины и удорожает конечную продукцию. 
Таблица 1

Параметры режимов уплотнения древесины

\begin{tabular}{|l|c|c|c|}
\hline \multicolumn{1}{|c|}{ Вид модификации } & $P, \mathrm{MПа}$ & $t,{ }^{\circ} \mathrm{C}$ & $\tau, \mathrm{c}$ \\
\hline Непрерывная усадка под давлением & $15-35$ & $140-160$ & 14400 \\
\hline Модификация со ступенчатым прессованием & $1,5-5$ & 135 & 2400 \\
\hline Модификация с предварительным нагревом & 5 & $135-140$ & 1200 \\
\hline $\begin{array}{l}\text { Модифицирование с предварительным пропа- } \\
\text { риванием }\end{array}$ & $15-29$ & $100-105$ & $2400-3600$ \\
\hline $\begin{array}{l}\text { Модификация с предварительной пропиткой } \\
\text { льняным маслом и воском }\end{array}$ & 15 & $140-160$ & 240 \\
\hline
\end{tabular}

В последнее время становится актуальным метод, при котором образцы древесины пропитываются экологически чистыми веществами, такими как льняное масло и воск. Для этого заготовки влажностью $W=15 \%$ пропитываются при комнатной температуре льняным маслом или раствором воска в льняном масле. Образцы пропитываются в 2 слоя, после каждого слоя происходит выдержка в течение суток. Далее образцы нагреваются в прессе до температуры $t=140-160^{\circ} \mathrm{C}$ и уплотняются в течение $240 \mathrm{c}$ при удельном давлении $P=5$ МПа. На конечном этапе происходит выдержка в плитах пресса до полного остывания. Достоинством данного метода является значительное сокращение времени прессования. Но при этом большую часть времени занимает пропитка образцов [2, 4-6].

Все показатели режимов обработки сведены в табл. 1.

Уплотнение древесины может быть поверхностным и объемным. Объемное уплотнение проводится для пропаренной или увлажненной до насыщения древесины, вследствие которого получается однородный по всему объему материал. Для проведения такого испытания расходуются большие количество времени и объем энергии. Преимуществом поверхностного метода прессования является то, что древесину необходимо нагревать только с той стороны, улучшение свойств которой требуется. Недостатками такого метода являются уменьшение степени уплотнения образцов со временем во влажных условиях, внутренние напряжения, возникающие при прессовании, которые приводят к короблению заготовок. Для уменьшения внутренних напряжений проводят термическую обработку образцов. Высокие температуры приводят к необратимому изменению химической структуры древесины. Данный процесс является экологически чистым, так как применяется только пар, воздух и тепло. Таким образом, данная технология может быть использована для значительного уменьшения степени распрессовки древесины.
Уплотнение древесины можно проводить как в позиционном оборудовании, так и в оборудовании проходного типа. Позиционное оборудование позволяет прессовать заготовки значительной толщины, в то время как на прокатных станках проходного типа удобно использовать образцы с малой толщиной.

Одним из самых механизированных методов является метод прокатки. Образцы предварительно нагревают до температуры $90-95^{\circ} \mathrm{C}$, после чего они проходят через несколько пар нагретых цилиндрических роликов с постепенным нарастанием уплотнения. Преимуществом данного метода является непрерывный процесс прессования, что в значительной степени увеличивает производительность оборудования и сокращает трудозатраты.

Известен способ, при котором образцы помещаются в пресс-формы, усыхают за счет чередования процессов увлажнения заготовок при погружении пресс-формы в воду и дальнейшей сушки в сушильной камере. Этот способ не позволяет достичь высокой степени уплотнения и является длительным и трудоемким.

Разновидностью уплотнения заготовок является поверхностное уплотнение вибрирующими нагретыми роликами. Такой метод позволяет получить поверхности высокого качества с глянцевым блеском. Уплотненная древесина данным способом плохо смачивается. Недостатками данного метода считается дорогостоящее оборудование.

Один из распространенных методов прессования древесины осуществляется с помощью гидравлических прессов. Образцы, предварительно высушенные до влажности $W=10 \pm 2 \%$, помещаются между нагретыми плитами пресса. В течение времени $\tau$ образцы находятся под давлением $P$. После снятия напряжения охлаждаются.

Для испытаний выбирают наиболее распространенные лиственные породы древесины. В лабораторных условиях заготовки получают из обрезной доски, соответствующей требованиям СТБ 1714-2007. В образцах не допускается наличие косослойности, свилеватости, 
сучков, трещин и других дефектов, способных оказать влияние на качество получаемой продукции. Строго регламентируется влажность древесины. Перед проведением испытаний образцы взвешиваются и замеряются их линейные размеры. Находится плотность каждого образца.

Для исследования будут рассмотрены методы только с применением непрерывной усадки под давлением или термического сжатия. Термическое сжатие - это метод модификации древесины, который сочетает в себе термические и механические процессы и приводит к уплотнению древесины. Основной целью комбинирования сжатия и нагрева древесины является улучшение физико-механических свойств древесины. Основной целью термомеханической модификации является преобразование химического состава древесины с помощью тепла, что приводит к изменению физической характеристики. Как известно, свойства модифицированной древесины можно регулировать в зависимости от режимов обработки, породы и начальной влажности.

В сводной табл. 2 приведены основные показатели режимов термомеханического модифицирования [7, 8-11].

Основой для выбора режима термомеханического модифицирования древесины являются показатели свойств, получаемые после обработки древесины. Необходимо учитывать, что при изменении одних свойств могут ухудшаться другие. Таким образом, стоит задача получения такого режима, при котором все свойства будут иметь оптимальные значения. Полученные образцы испытывают для нахождения твердости, износостойкости, влагопоглощения и шероховатости. Данные показатели являются основными при определении качества облицовочного покрытия.

Испытание твердости производится в соответствии с ГОСТ 16483.17-81. Приспособлении, состоящем из корпуса, пуансона с наконечником в виде полусферы радиусом $(5,64 \pm 0,01)$ мм. Образец помещают в приспособление, в него на определенную глубину вдавливается пуансон. При достижении заданной глубины вдавливания в образец определялась нагрузка $F$ с погрешностью не более $1 \%$. Статическая твердость образца $H_{w}^{\prime \prime}, \mathrm{H} / \mathrm{Mм}^{2}$, вычисляется по формуле

$$
H_{w}^{\prime \prime}=\frac{4 F}{3 \pi r^{2}} \text {. }
$$

Результаты исследований показывают, что уплотнение древесины и изменение твердости приводит к значительному увеличению плотности материала. Чем выше плотность, тем выше твердость и наоборот, данная зависимость имеет линейный характер.

Для измерения шероховатости можно использовать полуавтоматический профилографпрофилометр. На профилометрах с помощью щупа воспроизводят профиль поверхности. В щуп прибора устанавливается игла и располагается на испытываемом образце. Шероховатость определяют по шкале прибора, цифровому табло или по профилограмме и выводят данные на экран компьютера.

Испытание модифицированных образцов на влагопоглощение можно произвести с помощью эксикатора и взвешивания в соответствии с ГОСТ 16483.19-72. Вначале образцы взвешивают и отправляют в эксикатор, в который наливают насыщенный раствор соды. Периодически происходит взвешивание образцов. Минимальная продолжительность выдерживания образцов составляет 30 сут. Испытание заканчивается, когда разность между двумя последними взвешиваниями будет не более 0,002 г. Количество поглощенной влаги вычисляется по формуле

$$
w=\frac{m_{n}-m_{1}}{m_{1}-m} 100,
$$

где $m_{n}$ - масса бюксы с образцом, взвешенной через $n$ суток с момента первоначального помещения образца в эксикатор, г; $m_{1}-$ масса бюксы с образцом в абсолютно сухом состоянии, г; $m$ - масса бюксы, г.

Таблица 2

Режимы термомеханического модифицирования древесины лиственных пород

\begin{tabular}{|l|c|c|c|}
\hline \multicolumn{1}{|c|}{ Тема исследования } & $P, \mathrm{MПа}$ & $t,{ }^{\circ} \mathrm{C}$ & $\tau, \mathrm{c}$ \\
\hline $\begin{array}{l}\text { Влияние ультрафиолетового излучения на термо- } \\
\text { механически модифицированную древесину }\end{array}$ & 80 & $100-200$ & 180 \\
\hline $\begin{array}{l}\text { Особенности структурных изменений при термо- } \\
\text { механическом модифицировании древесины }\end{array}$ & $19,0-19,5$ & $100-110$ & $120-180$ \\
\hline $\begin{array}{l}\text { Микроскопическое исследование дефектов в терми- } \\
\text { чески спрессованных древесных панелях }\end{array}$ & 2 & 170 & 2700 \\
\hline $\begin{array}{l}\text { Влияние термической модификации на физические } \\
\text { войства древесины }\end{array}$ & 5 & 120 & 1800 \\
\hline
\end{tabular}


За показатель влагопоглощения принимается максимальная влажность древесины, выдержанной до прекращения влагопоглощения, но не менее 30 сут. [9, 12-15].

Заключение. Таким образом, для дальнейшего исследования модификации древесины лиственных пород необходимо на основе полученных данных сформировать диапазон каждого пара- метра для дальнейшего нахождения оптимального режима. В данном случае оптимальными параметрами будут следующие диапазоны: $P=$ $=5-15 \mathrm{MПа,} t=100-140^{\circ} \mathrm{C}, \tau=120-180 \mathrm{c}$. Выбор диапазона обоснован необходимостью разработки технологического режима термомеханического модифицирования для производства облицовочных панелей в промышленных масштабах.

\section{Список литературы}

1. Игнатович Л. В., Утгоф С. С. Особенности структурных изменений при термомеханическом модифицировании древесины сосны и ольхи // Труды БГТУ. 2015. № 2: Лесная и деревообрабатывающая промышленность. С. 130-136.

2. Хухрянский П. Н. Прессование древесины // Лесная промышленность. 1964. С. 351.

3. Тарбеева Н. А., Рублева О. А. Влияние режимов упрочняющей декоративной обработки на эксплуатационные характеристики изделий из древесины сосны // Сб. ст. XVIII Bсерос. науч.-практ. конф.: в 3 т. Вятка: Вятский гос. ун-т, 2018. Т. 2. С. 993-1000.

4. Шамаев В. А. Перспективы производства и применения модифицированной древесины // Научный журнал КубГАУ. 2012. № 78. URL: http://ej.kubagro.ru/2012/04/pdf/14.pdf (дата обращения: 20.10.2020).

5. Николин М. Е., Шейкман Д. В., Кошелева Н. А. Улучшение эксплуатационных свойств мягколиственных пород древесины модифицированием // VIII Всерос. науч.-техн. конф. студентов и аспирантов. М.: УГЛТУ. 2012. Ч. 1. С. 260-262.

6. Фомина О. А. Способы модифицирования древесины лиственных пород: отечественный и зарубежный опыт // Дневник науки. 2017. № 9. URL: https://www.elibrary.ru/item.asp?id=30360480 (дата обращения: 18.10 .2020$)$.

7. Dogu D., Tirak Hizal K., Bakir D., Tuncer F. D., Candan Z., Ünsal Ö. Anatomical Structures of Thermally Compressed Paulownia Wood // Proceedings of the 58th International Convention of Society of Wood Science and Technology, Wyoming. 2015. P. 304-304.

8. Dilek D., Davut B., Tuncer F. D., Hizal K. T., Unsal O., Candan Z. Microscopic investigation of defects in thermally compressed poplar wood panels // Woods: Science and Technology. 2016. No. 18. P. 337-348.

9. Gonca Düzkale Sözbir, İbrahim Bektaș. The Effect of Heat Modification and Densification on Physical Properties of Poplar Wood // Wood industry. 2017. No. 68. P. 315-321.

10. Бекешива М. А., Колесникова А. А. Сравнительный анализ прочности древесины тополя, модифицированной различными способами // Технические науки. 2018. № 13. URL: http:// novaum.ru/public/p738 (дата обращения: 18.10.2020).

11. Batista D. C., Paes J. B., Bolzón De Muñiz G. I., Nisgoski S., Da Silva Oliveira J. T. Microstructural aspects of thermally modified Eucalyptus grandis wood // Woods: Science and Technology. 2015. No. 17. P. 525-532.

12. Laskowska A. The influence of ultraviolet radiation on the colour of thermo-mechanically modified beech and oak wood // Woods: Science and Technology. 2020. Vol. 22. No. 1. P. 55-68.

13. Candan Z., Korkut S., Unsal O. Thermally compressed Poplar wood. Physical and mechanical properties // Wood industry. 2013. No. 64. P. 107-211.

14. Kutnar A., Widmann R., Kamke F. A. Density, mechanical properties, and morphology of densified wood in relation to compression temperature and steam environments // Proc. of 8th European Conference on Wood Modification, Ljubljana, Slovenia. 2012. P. 167-174.

\section{References}

1. Ignatovich L. V., Utgof S. S. Features of structural changes during thermomechanical modification pine and alder wood. Trudy BGTU [Proceedings of BSTU], 2015, no. 2: Forest and Woodworking Industry, pp. 130-136 (In Russian).

2. Khukhryanskiy P. N. Pressing wood. Lesnaya promyshlennost' [Forest industry], 1964, pp. 351 (In Russian).

3. Torbeeva N. A., Rubleva O. A. Influence of modes of strengthening decorative processing on operational characteristics of products made of pine wood. Sbornik statey XVIII Vserosiyskoy nauchnoprakticheskoy konferentsii: $v 3 t$. [Collection of articles of the XVIII all-Russian scientific and practical conference: in 3 vol.]. Vyatka, 2018, vol. 2, pp. 993-1000 (In Russian). 
4. Shamaev V. A. Prospects of production and application of modified wood. Nauchnyy zhurnal KubGAU, 2012, no. 78 (In Russian). Available at: http://ej.kubagro.ru/2012/04/pdf/14.pdf (accessed 20.10.2020).

5. Nikolin M. E., Shyekman D. V., Kosheleva N. A. Improvement of operational properties of softleaved wood species by modification. VIII Vserosiyskaya nauchno-tekhnicheskaya konferentsiya studentov $i$ aspirantov [VIII all-Russian scientific and technical conference of undergraduate and graduate students]. Moscow, 2012, part 1, pp. 260-262 (In Russian).

6. Fomina O. A. Methods of modifying hardwood: domestic and foreign experience. Dnevnik nauki, 2017, no. 9 (In Russian). Available at: https://www.elibrary.ru/item.asp?id=30360480 (accessed 18.10.2020).

7. Dogu D., Tirak Hizal K., Bakir D., Tuncer F. D., Candan Z., Ünsal Ö. Anatomical Structures of Thermally Compressed Paulownia Wood. Proceedings of the 58th International Convention of Society of Wood Science and Technology. Wyoming, 2015, pp. 304-304.

8. Dilek D., Davut B., Tuncer F. D., Hizal K. T., Unsal O., Candan Z. Microscopic investigation of defects in thermally compressed poplar wood panels. Woods: Science and Technology, 2016, no. 18, pp. 337-348.

9. Gonca Düzkale Sözbir, İbrahim Bektaş. The Effect of Heat Modification and Densification on Physical Properties of Poplar Wood. Wood industry, 2017, no. 68, pp. 315-321.

10. Bekisheva M. A., Kolesnikova A. A. Comparative analysis of the strength of poplar wood modified in various ways. Tekhnicheskiye nauki, 2018, no. 13 (In Russian). Available at: http://novaum.ru/public/p738 (accessed 18.10.2020).

11. Batista D. C., Paes J. B., Bolzón De Muñiz G. I., Nisgoski S., Da Silva Oliveira J. T. Microstructural aspects of thermally modified Eucalyptus grandis wood. Maderas. Woods: Science and Technology, 2015 , no. 17 , pp. 525-532.

12. Laskowska A. The influence of ultraviolet radiation on the colour of thermo-mechanically modified beech and oak wood. Woods: Science and Technology, 2020, vol. 22, no. 1, pp. 55-68.

13. Candan Z., Korkut S., Unsal O. Thermally compressed Poplar wood. Physical and mechanical properties. Wood industry, 2013, no. 64, pp. 107-211.

14. Kutnar A., Widmann R., Kamke F.A. Density, mechanical properties, and morphology of densified wood in relation to compression temperature and steam environments. Proc. of 8th European Conference on Wood Modification. Ljubljana, Slovenia, 2012, pp. 167-174.

\section{Информация об авторах}

Утгоф Светлана Сергеевна - кандидат технических наук, старший преподаватель кафедры технологии и дизайна изделий из древесины. Белорусский государственный технологический университет (220006, г. Минск, ул. Свердлова, 13а, Республика Беларусь). E-mail: utgof@belstu.by

Куневич Валерия Олеговна - магистрант кафедры технологии и дизайна изделий из древесины. Белорусский государственный технологический университет (220006, г. Минск, ул. Свердлова, 13a, Республика Беларусь).

\section{Information about the authors}

Utgof Svetlana Sergeevna - PhD (Engineering), Senior Lecturer, the Department of Technology and Design of Wooden Articles. Belarusian State Technological University (13a, Sverdlova str., 220006, Minsk, Republic of Belarus).E-mail: utgof@belstu.by

Kunevich Valeria Olegovna - Master's degree student, the Department of Technology and Design of Wooden Articles. Belarusian State Technological University (13a, Sverdlova str., 220006, Minsk, Republic of Belarus). 